\title{
Test Method Validation for Quantitative Determination of Heavy Metals in Olive Oils by Inductive Coupled Plasma (ICP - AES) using Low Cost and Simple Extraction Method Haggag $S^{1}$., M. Saif ${ }^{2}$ and H. S. Hafez ${ }^{1 *}$
}

${ }^{1}$ Nano-Photochemistry and its Environmental Applications Laboratory, Environmental Studies and Research Institute (ESRI), University of Sadat City, Sadat City, 32897 Menofia, Egypt

${ }^{2}$ Department of Chemistry, Faculty of Education, Ain Shams University, Roxy, 11711 Cairo, Egypt.

\section{ABSTRACT}

The aim of this study is to demonstrate a valid and simple extraction method for the extraction of heavy metals from olive oil and its quantitative determination by ICPAES technique. Fifteen olive oil samples are collected from different manufacturing companies originates from five countries. Fourteen metals are quantitively detected in all samples including; Aluminum, Arsenic, Calcium, Cadmium, Cobalt, Chromium, Copper, Iron, Potassium, Magnesium, Manganese, Nickel, Lead and Zinc. A simple extraction method has been proposed for the extraction of heavy metals from the raw oil samples based on diluted $10 \% \mathrm{HNO}_{3}$. Test method validation procedures have been carried out for the quantitative analytical determination of the detected trace metals in the investigated oil samples. The trace elements are found to be in the concentration range from 0.0001 to $8.39 \mathrm{mg} \cdot \mathrm{kg}^{-1}$. As a result of the test method validation; linearity $(\mathrm{R} 2)$ is above 0.99 , the recovery ranged between $(72.63 \%$ to $124.62 \%)$, the limit of detection and the limit of quantitation are between $(0.006-$ $\left.2.32 \mu \mathrm{g} . \mathrm{kg}^{-1}\right)$ and $\left(0.022-7.68 \mu \mathrm{g} . \mathrm{kg}^{-1}\right)$ respectively. The relative standard deviation (RSDs) for repeatability and ruggedness are found to be lower than $2.2 \%$ for selected elements, which confirms the precision of the ICP-AES analytical method. The results demonstrate the validity of accurate, precise, rugged, selective, specific and stable ICP-AES determination method for trace metal analysis in raw olive oil samples that based on the proposed simple extraction method.

Key words : Heavy metals; ICP-AES; Olive oil; Method validation

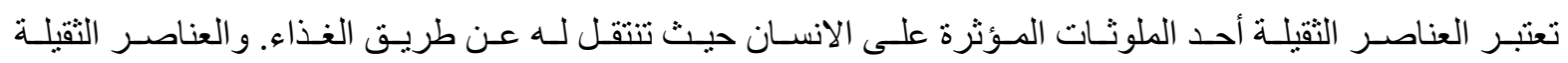

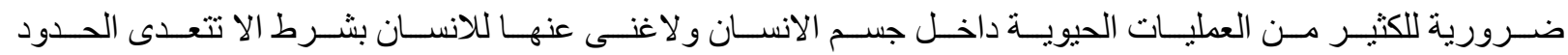

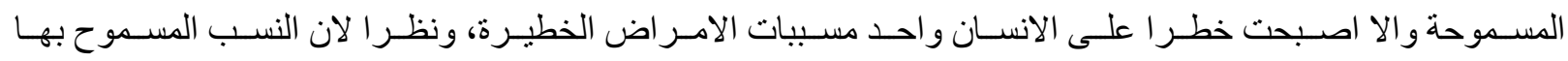
ضئيلة جدا كان لابد من وجود طرق وتقنيات دقيقة لرصد كميات العناصر الثقيلة في الغذاء. من هذا المنطلق فان الهدف الأساسي من هذه الدر اسة يتضمن:

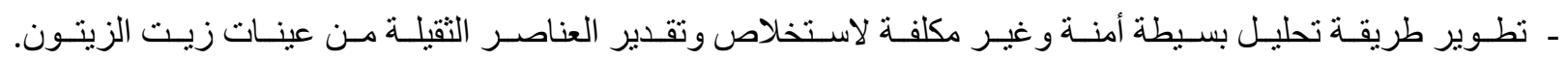

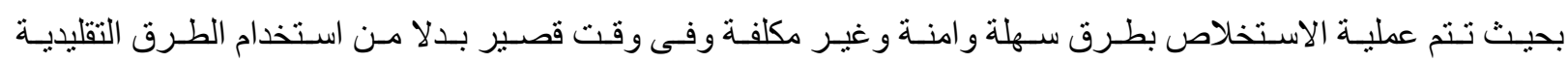

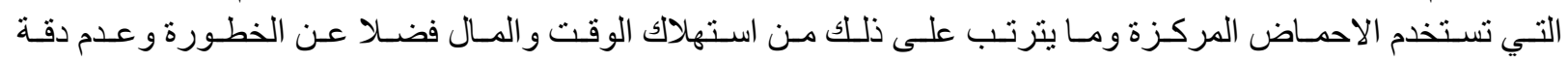
النتائج.

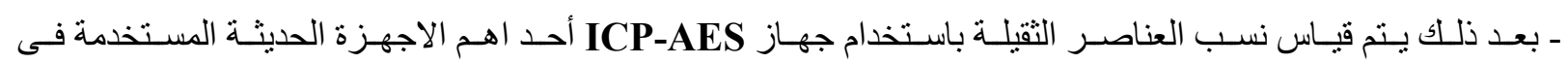
رصد العناصر عند تركيزات منخفضة حيث بتميز بالدقة و الحساسية. 


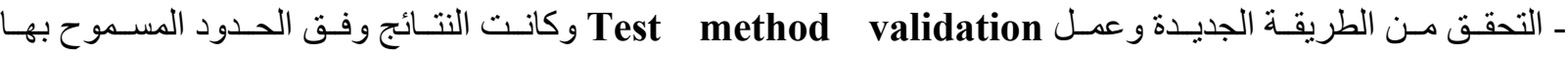

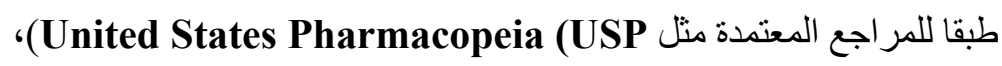

$$
\text { ـنطبيق الطريقة على عدد من العينات والتأكد من النتائج. }
$$

\section{INTRODUCTION}

The metal contents in vegetable oils are important because of toxicological as well as their nutritional viewpoints. Trace metals present in oils may be of natural origin or present due to processing procedures. It is possible to find the presence of metals due to a variety of factors such as treatment processes (by processing steps as bleaching, hardening, refining and deodorization, as well as corrosion of the processing equipment's), packaging procedures, from water plumbing, presence of fungicide residues used in agriculture or the presence of highways, industries near the site of cultivation (Ansari,et al.,2009 ; Cypriano, et al.,2008; Dugo, et al.,2004 ; Şahan,et al.,2007).

The determination of trace metal content in vegetable oils is an important criterion for the assessment of oil quality with regard to freshness, keeping properties, storage and their influence on human nutrition and health. Many reports have described the deleterious effects that trace metal has on the flavor and oxidative stability of oils, since some metals could catalyze oxidation of fatty acid chains, exerting a deleterious influence on shelf life and nutritional value (Díaz, et al.,2006; Cabrera-Vique, et al.,2012; Martin-Polvillo, et al.,1994).However, the accurate determination of trace metals in this kind of samples is still an analytical challenge, owing to their low concentration level and the difficulties that arise due to the characteristics of the matrix (Nunes, et al.,2011).

A variety of inorganic techniques can be used to measure trace elements in raw samples including atomic absorption spectrometry (AAS), inductively coupled plasma with mass spectrometry (ICP-MS) and inductively coupled plasma atomic emission spectrometry (ICP-AES). AAS is the most common technique used for $\mathrm{m}$

However, in general, atomic spectrometric methods for metals determination in organic matrix present some disadvantages, such as the reduced stability of the analytes in the solution, the need of organometallic standards for calibration, and the use of dangerous organic solvents or sample digestion with an acid or acid mixture (de Souza, et al.,2008).

metals determination in vegetable oils (De Leonardis, et al.,2000).

*Corresponding author: ${ }^{1}$ H. S. Hafez; Environmental Studies and Research Institute, University of Sadat City; Menofia, Egypt. P.O. 32897; Tel: +2 01009463473; Fax: +2 048 2600404; E:mail; hoda.hafez@esri.usc.edu.eg; https://orcid.org/0000-0002-8574-1451 
Inductively coupled plasma atomic emission spectrometry (ICP-AES) is a powerful technique for trace analysis of elements which is preferred for ultra-trace levels due to its higher sensitivity (Karadjova, et al.,1998). Atomic emission spectroscopy coupled with inductively coupled plasma (ICP-AES) is a multi-element technique that can be effectively used for analyzing oil samples, that will be characterized by high selectivity, sensitivity and detection limits much lower than other multi-element techniques. However, this method of quantitative analysis requires a pretreatment step for the extraction of trace elements from the oil content. Classical extraction methods usually employed are wet digestion (Jovanovic, et al.,2003), dry aching (Raptis, et al.,1982), acid extraction (De Leonardis, et al.,2000), and microwave assisted heating (Şahan, et al.,2007). However, these methods are time consuming and may lead to destruction of organic content as well as loss of some volatile metals in the samples. Therefore, the application of non-destructive, low cost and simple extraction method as a preliminary step in the determination of trace heavy metals in oil samples, is a crucial step in the quantitative determination of trace elements in vegetable oils.

In this work of research, a preliminary simple extraction method that based on diluted Nitric acid has been proposed for the extraction of heavy metals from 15 raw olive oil samples collected from different manufacturing companies originates from five countries. This followed by quantitative determination of 14 heavy metals including ( $\mathrm{Al}, \mathrm{As}, \mathrm{Ca}, \mathrm{Cd}, \mathrm{Co}, \mathrm{Cr}, \mathrm{Cu}, \mathrm{Fe}, \mathrm{k}, \mathrm{Mg}, \mathrm{Mn}, \mathrm{Ni}, \mathrm{Pb}$, and $\mathrm{Zn}$ ) in the investigated oil samples. For accurate and precise results, test method validation has been investigated in terms of linearity (R2); Precision; Accuracy; Selectivity and Specificity; Limit of detection and limit of quantitation.

\section{Experimental}

\subsection{Instrumentation}

Inductively Coupled Plasma /Atomic Emission Spectroscopy (ICP-AES), Multi type ICP Emission Spectrometer (ICPE-9000, SHEMADZU Corporation, Japan), is used for the quantitative determination of trace elements in the oil samples. The Instrument is used with a micro mist nebulizer and silica cyclonic spray chamber and continuous nebulization. The operating conditions of the ICP-AES are given in Table

Prior to analysis, the ICP-AES located in a temperature-controlled laboratory $\left(20 \pm 2{ }^{\circ} \mathrm{C}\right)$, is allowed for a sufficient period of time to be stabilized before optimization. 
Table 1. The operational conditions and instrumental description of ICP-AES.

\begin{tabular}{|l|l|}
\hline Subject & Descriptions \\
\hline Ignition Mode : & Normal. \\
\hline Attached Instruments: & Mini Torch. \\
Radio Frequency power: & $1.20 \mathrm{KW}$. \\
\hline PLASMA Gas : & $\mathbf{1 0 . 0 0 ~ L / m i n . ~}$ \\
Auxiliary gas : & $\mathbf{0 . 6 0} \mathrm{L} / \mathrm{min}$. \\
\hline Carrier Gas : & $\mathbf{0 . 7 0 ~ L / m i n . ~}$ \\
Exposure Time : & $\mathbf{3 0 ~ s e c . ~}$ \\
Condition: & Wide Range. \\
Solvent Rinse : & $\mathbf{3 0}$ sec. \\
\hline Sample Range : & $\mathbf{3 0}$ sec. \\
\hline
\end{tabular}

\subsection{Samples and Reagents}

Fifteen olive oil samples are collected from different manufacturing companies originates from five countries, as the origin of samples was from; Egypt, Palastine, Syria, Saudi Arabia and Jordan. Three samples are collected from each vendor.

Ultra-pure de-ionized water $\left(18 \mathrm{M} \Omega \mathrm{cm}^{-1}\right)$ from a Milli-Q analytical reagent-grade water purification system (Millipore) was used for all preparation procedures. Ultrapure $\mathrm{HNO}_{3} 69 \%$ from J.T. Baker, was used for sample pre-treatment. Multi-element standard solutions from; Al, As, Ca, Cd, Co, Cr, Cu, Fe, K, Mg, Mn, Ni, Pb, Zn (100 mg. $\mathrm{L}^{-1}$ ) from AppliChem; Germany, were used for calibrations.

\subsection{Experimental Methods}

\subsubsection{Methods of analysis}

\subsubsection{Calibration}

Standard calibration curves are carried out using different conc. of multi element standard solutions from each element under investigation in diluted $10 \% \mathrm{HNO}_{3}$ ranged from 0.005 to $2.5 \mathrm{mg} . \mathrm{kg}-1$, according to the expected concentrations of each elements. A $10 \%$ diluted solution from $\mathrm{HNO} 3$ was used as a blank. The results obtained were evaluated based on the intensity of the corrected blank. The intensity of metals determination in vegetable oils (De Leonardis, et al.,2000).

*Corresponding author: ${ }^{1}$ H. S. Hafez; Environmental Studies and Research Institute, University of Sadat City; Menofia, Egypt. P.O. 32897; Tel: +2 01009463473; Fax: +2 048 2600404; E:mail; hoda.hafez@esri.usc.edu.eg; https://orcid.org/0000-0002-8574-1451 
a series of standard metal solutions for each element was recorded with the ICP-AES after setting the instrument as per optimum conditions (Table 2.1.). Then the peak intensity was plotted against the corresponding concentration in $\mathrm{mg} \cdot \mathrm{L}^{-1}$ for each metal. The regression coefficient for each calibration graph was calculated to check linearity for each metals. The following spectral lines (wavelengths in $\mathrm{nm}$ ) were chosen and monitored for each metal; Al-396.153; As-228.812; Ca- 422.673; Cd226.502; Co-228.616; Cr-267.716; Cu-324.754; Fe- 238.204; K- 766.490; $\mathrm{Mg}$ 285.213; Mn-257.610; Ni-221.647; Pb-405.783; Zn-213.856.

\subsubsection{Sample collection, preservation and storage}

The samples were representative and individually placed in Brown polythene bottles and transported to the laboratory, where they were kept and protected from light in cold area before analysis.

\subsubsection{Extraction and Sample preparation for ICP-AES}

A 5.0 gram of each olive oil sample was weighted directly into a polyethylene centrifuge tube. Then $5.0 \mathrm{~mL}$ of $10 \%$ dilute nitric acid was added. The oil-acid mixture was shaken vigorously and then vortex for 2.0 minutes until the layers were completely mixed. The capped centrifuge tubes were placed in shaking water bath at $50^{\circ} \mathrm{C}$ for $30 \mathrm{~min}$. The sample tubes were centrifuged at $2800 \mathrm{rpm}$ for $10 \mathrm{~min}$ at $30^{\circ} \mathrm{C}$. After which, the lower acid aqueous layer was withdrawn with a pipette and then loaded directly into the auto sampler of the ICP-AES.

\subsubsection{Quality control}

To assure the correctness of the data reported, recovery experiments were performed at three different levels of concentrations. A certain amount of each element of interest in dependency on its expected concentration in the sample extract, was added prior to mineralization to three different oil samples. The experiments were performed in triplicate to avoid contamination and interference with the specimens. All steps of the sample preparation procedure were carried out in a laboratory equipped for trace element analyses. Reagent blanks were prepared and measured in the same way as the samples. The stability of selected metal concentrations in the samples were checked every $30 \mathrm{~min}$, for $240 \mathrm{~min}$ during test method development. The signal was stable during the monitoring time, indicating stability of the analytes.

\subsubsection{Statistical Methods}

All the statistical analytical methods are presented and calculated for standards and three replicates from each sample in terms of Mean; Relative Standard Deviation; Linearity; Limit of Detection and Limit of Quantitation.

\subsubsection{Linearity}

The calibration curves were plotted using Eq. 1:

$$
\mathrm{y}=\mathrm{ax}+\mathrm{b} \quad \text { Eq. } 1
$$


Where $\mathrm{y}$ is the signal intensity and $\mathrm{x}$ is the know concentration of the given analyte in the calibration solution.

\subsubsection{Standard deviation and Relative standard deviation}

The standard deviation (S) and relative standard deviation (RSD) are calculated using the following equation (Ball,1979).

$s=\sqrt{\Sigma\left(x_{t}-x^{-}\right) 2} /(n-1) \quad$ Eq. 2

$\mathrm{S}$ is the standard deviation, $x^{-}$is the mean value, $x_{i}$ is the actual value and $\mathrm{n}$ is the number of determinations.

$\mathrm{RDS} \%=\left(\mathrm{S} / x^{-}\right) \times 100$

Eq. 3

$\mathrm{RDS}=$ Relative standard deviation

\subsubsection{Limit of detection and limit of quantitation}

The limit of detection was calculated using the following equations (Wenzl, et al.,2016).
$\mathrm{X}_{\mathrm{LOD}}=3.9 * \mathrm{~S}_{\mathrm{y}, \mathrm{b}} / \mathrm{b}$
Eq. 4
$\mathrm{X}_{\text {LOQ }}=3.3 * \mathrm{X}_{\text {LOD }}$
Eq. 5

Where: LOD is the limit of detection, LOQ is the limit of quantitation, $\mathrm{S}_{\mathrm{y}, \mathrm{b}}$ is the standard deviation of the blank signals and $b$ is the slope of calibration curve. The LODs were calculated as the concentration equivalent to three times the standard deviation (3r) of the signal of the blank solution. In addition, the accuracy of the method and precision were estimated from the equation of calibration curve as a concentration.

\section{Results and discussion}

\subsection{Test Method Validation}

A test method validation for the quantitative determination of 14 heavy metals (Al, $\mathrm{As}, \mathrm{Ca}, \mathrm{Cd}, \mathrm{Co}, \mathrm{Cr}, \mathrm{Cu}, \mathrm{Fe}, \mathrm{K}, \mathrm{Mg}, \mathrm{Mn}, \mathrm{Ni}, \mathrm{Pb}$ and $\mathrm{Zn}$ ) in olive oils by ICP-AES technique has been verified in terms of; linearity (R2); Precision; Accuracy; Selectivity and Specificity; Limit of detection and limit of quantitation; Repeatability and Ruggedness. The results are given below.

\subsubsection{Linearity}

Using standard calibration solutions from each metal, the linearity of the calibration curve corresponding to each metal has been calculated according to Eq. 1 and the data are given in Table 2. From the results of the correlation coefficient values $\left(\mathrm{R}^{2}\right)$ is found to be higher than 0.99 for most of the metals. Which can be considered as acceptable values (USP,2007).

metals determination in vegetable oils (De Leonardis, et al.,2000).

*Corresponding author: ${ }^{1}$ H. S. Hafez; Environmental Studies and Research Institute, University of Sadat City; Menofia, Egypt. P.O. 32897; Tel: +2 01009463473; Fax: +2 048 2600404; E:mail; hoda.hafez@esri.usc.edu.eg; https://orcid.org/0000-0002-8574-1451 
Table 2. Statistical parameters for the standard calibration curves for the metals under investigation.

\begin{tabular}{|c|c|c|c|c|c|}
\hline $\begin{array}{l}\text { Sampl } \\
\text { e No. }\end{array}$ & Element & $\begin{array}{l}\text { Wavelength } \\
(\mathrm{nm})\end{array}$ & $\begin{array}{l}\text { Intercept } \\
\text { (b) }\end{array}$ & $\begin{array}{l}\text { Slope } \\
\text { (a) }\end{array}$ & $\begin{array}{l}\text { Correlation } \\
\text { coefficient }\left(R^{2}\right)\end{array}$ \\
\hline 1 & $\mathrm{Al}$ & 396.153 & 546.02 & 2052.18 & 0.9990 \\
\hline 2 & As & 228.812 & 219.10 & 1450.19 & 0.9996 \\
\hline 3 & $\mathrm{Ca}$ & 422.673 & 6033.0 & 131.380 & 0.9983 \\
\hline 4 & $\mathrm{Cd}$ & 226.502 & 240.83 & 6249.20 & 0.9998 \\
\hline 5 & $\mathrm{Co}$ & 228.616 & 213.22 & 3895.40 & 0.9999 \\
\hline 6 & $\mathrm{Cr}$ & 267.716 & 223.13 & 4348.80 & 0.9999 \\
\hline 7 & $\mathrm{Cu}$ & 324.754 & 1128.0 & 10532.0 & 0.9999 \\
\hline 8 & $\mathrm{Fe}$ & 238.204 & 413.59 & 6766.00 & 0.9968 \\
\hline 9 & $\mathrm{~K}$ & 766.490 & 1546.8 & 7195.20 & 0.9977 \\
\hline 10 & $\mathrm{Mg}$ & 285.213 & 2226.1 & $\begin{array}{l}13201 . \\
0\end{array}$ & 0.9989 \\
\hline 11 & $\mathrm{Mn}$ & 257.610 & 419.46 & $\begin{array}{l}33549 . \\
0\end{array}$ & 0.9999 \\
\hline 12 & $\mathrm{Ni}$ & 221.647 & 182.78 & $\begin{array}{l}2441.0 \\
0\end{array}$ & 0.9999 \\
\hline 13 & $\mathrm{~Pb}$ & 405.783 & 913.95 & $\begin{array}{l}289.97 \\
0\end{array}$ & 0.9962 \\
\hline 14 & $\mathrm{Zn}$ & 213.856 & 285.57 & $\begin{array}{l}1553.2 \\
0\end{array}$ & 0.9995 \\
\hline
\end{tabular}

\subsubsection{Selectivity and Specificity}

To study the selectivity of the proposed method, the signal of each target metal has been recorded in the presence of the other metals in the same matrix at different wavelengths (3-5 wavelengths). The selected wavelength for each target metal has been determined by that at which there is absolute absence of any interference effect. This has been automatically done by the ICP-AES machine. As the selected wavelength has been done based on good linearity, accuracy and recovery. The selected and specific wavelength for each metal under investigation in 
this study is given in Table 2. The absolute interference effects at the selected wavelengths means that the specificity of the proposed method equals $100 \%$. According to IUPAC, 2002, specificity $=100 \%$ selectivity (Taverniers, et al.,2010).

\subsubsection{Limit of detection and limit of quantitation}

The analytical sensitivity of ICP-AES has been evaluated by determining the values of limit of detection (LOD) and limit of quantitation (LOQ). The limit of detection (LOD) have been determined by using pseudo-blank sample which has been analyzed ten replicates under repeatability conditions. The limit of detection is calculated using Eq. 2, and the data are given in Table 3.

The limit of quantification (LOQ) which is expressed as the lowest concentration that can be quantitatively determined with an acceptable level of repeatability and accuracy by the ICP-AES technique. The values of LOQ of the metals under investigation are calculated using Eq. 3 and the data are given in Table 3 and presented in Fig. 1. Based on LOD values, ICP-AES is demonstrated to be a sensitive enough for analysis of these heavy metals because LOD values are lower than maximum values of heavy metals allowed to be present in olive oils, i.e. $0.1 \mathrm{mg}$. $\mathrm{Kg}^{-1}$ (Codex, 2013).

Table 3. LOD and LOQ of the metals determined by the current ICP-AES.

\subsubsection{Accuracy}

Accuracy is determined by comparing the measured concentration of each metal with its certified values and is expressed as percentage recovery $R$ [\%] (Voica, et al.,2012).

In this study, three spiked solutions of the metals with three concentrations $(0.1,1.0$, and $2.0 \mathrm{mg} / \mathrm{kg})$ are prepared by spiking specific volume from each metals stock solutions into a pseudo-blank sample. These solutions are analyzed by the ICPAES technique. Three runs are performed for every concentration, and the responses are then recorded. The percentage recovery of each metal in pseudo-blank is calculated by proportion of the concentration of the element found in the spiked recovery solution (which is obtained from the calibration curve) to the theoretical concentration of that metal. The average recovery and the RSD for each level is then calculated. Results are given in Table 4 and presented in Fig. 2. As it can be well observed that the recovery $\%$ varies from $72.63 \%$ to $124.62 \%$. These results demonstrate a high accuracy for the ICP-AES technique used in this study (USP,2007).

metals determination in vegetable oils (De Leonardis, et al.,2000).

*Corresponding author: ${ }^{1}$ H. S. Hafez; Environmental Studies and Research Institute, University of Sadat City; Menofia, Egypt. P.O. 32897; Tel: +2 01009463473; Fax: +2 048 2600404; E:mail; hoda.hafez@esri.usc.edu.eg; https://orcid.org/0000-0002-8574-1451 
Table 4. The Recovery (\%) for three replicates of each metal under investigation.

\begin{tabular}{rrrr}
\hline Metal & \multicolumn{3}{l}{ Spiked Concentration, $\mathbf{~ m g . k g}^{-\mathbf{1}}$} \\
\cline { 2 - 4 } & & $\mathbf{1 . 0}$ & $\mathbf{2 . 0}$ \\
$\mathbf{A l}$ & 96.670 & 92.420 & 100.74 \\
$\mathbf{A s}$ & 75.820 & 94.150 & 96.920 \\
$\mathbf{C a}$ & 124.62 & 116.36 & 116.12 \\
$\mathbf{C d}$ & 81.770 & 92.770 & 97.900 \\
$\mathbf{C o}$ & 83.470 & 94.310 & 99.750 \\
$\mathbf{C r}$ & 90.110 & 94.510 & 99.740 \\
$\mathbf{C u}$ & 98.670 & 96.830 & 100.98 \\
$\mathbf{F e}$ & 105.73 & 99.200 & 98.810 \\
$\mathbf{K}$ & 122.81 & 118.18 & 112.90 \\
$\mathbf{M g}$ & 107.65 & 100.71 & 108.19 \\
$\mathbf{M n}$ & 93.870 & 94.910 & 99.680 \\
$\mathbf{N i}$ & 79.670 & 93.610 & 98.910 \\
$\mathbf{P b}$ & 96.450 & 101.87 & 114.06 \\
$\mathbf{Z n}$ & 72.630 & 91.880 & 96.900 \\
& & & \\
\hline
\end{tabular}

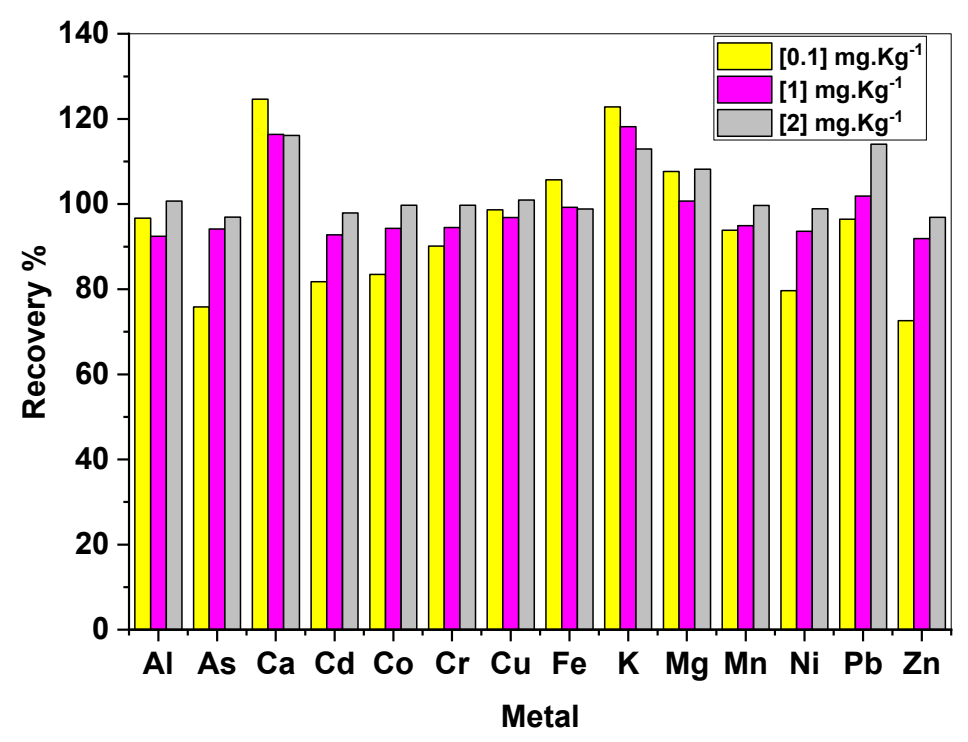

Fig. 2. Bar presentation of Recovery $\%$ of the metals determined by the current ICP-AES.

\subsubsection{Precision}

The precision expresses as the closeness of agreement (degree of scatter) between a series of measurements obtained from multiple sampling of the same homogenous sample under the prescribed conditions ( $\mathrm{ICH}, 2005)$. In this study, precision is evaluated by measuring the values of relative standard deviation (RSD) of a set of 
data. The assessments are done by determining RSD under the conditions of repeatability and intermediate precision (Ruggedness).

\subsubsection{Repeatability}

The repeatability test has been done by measuring each metal at a certain conc. 1.0 $\mathrm{mg} / \mathrm{kg}$, of six replicate samples for the fourteen metals. The relative standard deviation (RSD) is then calculated and tabulated in Table 5. The results showed that the $\%$ recovery obtained is very close to that obtained by the main analyst and the relative standard deviation is found to be less than $1.6 \%$ for all metals at the concentration level $1.0 \mathrm{mg} / \mathrm{kg}$ (Table 5). These results confirm that the current method is a repeatable. As, the acceptance criteria for the relative standard deviation: (Not More Than (NMT) 20\% for the six replicates for each metal (USP,2007).

Table 5. The RSD for repeatability of six replicates of $1.0 \mathrm{mg} / \mathrm{kg}$ for each metal under investigation using ICP-AES method.

\begin{tabular}{|c|c|c|}
\hline Metal & RSD & $\begin{array}{l}\text { Acceptance } \\
\text { Criteria }\end{array}$ \\
\hline Al & 0.325470 & \multirow{13}{*}{ RSD NMT $20.0 \%$} \\
\hline As & 0.729555 & \\
\hline $\mathrm{Ca}$ & 1.524821 & \\
\hline Cd & 0.239181 & \\
\hline Co & 0.381867 & \\
\hline $\mathrm{Cr}$ & 0.417869 & \\
\hline $\mathrm{Cu}$ & 0.344410 & \\
\hline $\mathbf{F e}$ & 0.504340 & \\
\hline $\mathbf{K}$ & 0.727826 & \\
\hline Mg & 0.877521 & \\
\hline Mn & 0.742902 & \\
\hline $\mathbf{N i}$ & 0.568289 & \\
\hline $\mathbf{P b}$ & 0.474491 & \\
\hline
\end{tabular}

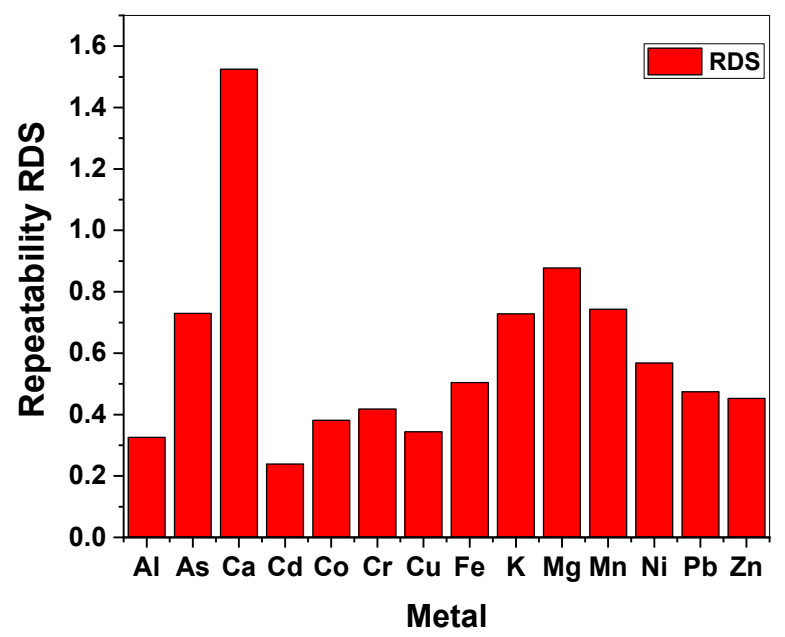

Fig. 3. Bar presentation of the RSD for repeatability of six replicates of $1.0 \mathrm{mg} / \mathrm{kg}$ from each metal under investigation using ICP-AES method.

metals determination in vegetable oils (De Leonardis, et al.,2000).

*Corresponding author: ${ }^{1}$ H. S. Hafez; Environmental Studies and Research Institute, University of Sadat City; Menofia, Egypt. P.O. 32897; Tel: +2 01009463473; Fax: +2 048 2600404; E:mail; hoda.hafez@esri.usc.edu.eg; https://orcid.org/0000-0002-8574-1451 


\section{\begin{tabular}{l|l} 
Zn & 0.452243
\end{tabular}}

\subsection{7.}

\subsubsection{Intermediate Precision (Ruggedness)}

Ruggedness has been tested by measuring the repeatability of the result obtained with the same method, on the same sample, in the same laboratory, but by different operators and in different day of measurements. And then calculation of the \% recovery of the metals at concentration level $(1.0 \mathrm{mg} / \mathrm{kg})$ for 12 replicates. The results showed that the $\%$ recovery obtained is very close to that obtained by the main analyst and the calculated relative standard deviation is found to be less than $2.2 \%$ (Table 6 and Fig. 4). These results confirms that RSD comply with the United States Pharmacopeia (USP) acceptance criteria and this method is rugged(USP,2007).

Table 6. The RSD of ruggedness of 12 replicates of $1.0 \mathrm{mg} / \mathrm{kg}$ for each metal under investigation using ICP-AES method

\begin{tabular}{|c|c|c|}
\hline Metal & RSD & Acceptance Criteria \\
\hline Al & 0.581458 & \multirow{14}{*}{ RSD NMT $25.0 \%$} \\
\hline As & 0.672697 & \\
\hline Ca & 1.154602 & \\
\hline Cd & 0.195704 & \\
\hline Co & 1.008592 & \\
\hline $\mathrm{Cr}$ & 0.431181 & \\
\hline $\mathbf{C u}$ & 0.388933 & \\
\hline $\mathbf{F e}$ & 0.656382 & \\
\hline $\mathbf{K}$ & 0.768663 & \\
\hline Mg & 0.836423 & \\
\hline Mn & 1.350211 & \\
\hline $\mathbf{N i}$ & 0.458026 & \\
\hline $\mathbf{P b}$ & 2.169847 & \\
\hline Zn & 0.369972 & \\
\hline
\end{tabular}

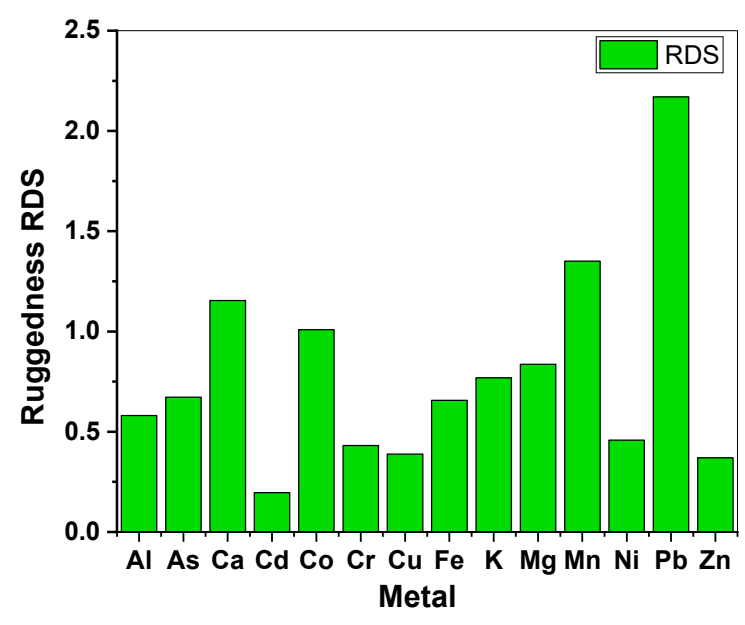

Fig. 4. Bar presentation of the RSD of ruggedness of 12 replicates of $1.0 \mathrm{mg} / \mathrm{kg}$ for each metal under investigation using ICPAES method.

\subsection{Application of the method to olive oil samples}

After successful development and validation of the ICP-AES method for the simultaneous determination of the fourteen metals under investigation, Fifteen olive oil samples collected form different manufacturing companies originates from five countries have been analyzed using this technique and the results are given in Table 7. 
The detection power of the ICP-AES technique was sufficient for the determination of $\mathrm{Ca}, \mathrm{Fe}, \mathrm{Mg}, \mathrm{K}$, and $\mathrm{Zn}$ in all olive oil samples. The other analytes ( $\mathrm{Al}, \mathrm{As}, \mathrm{Cd}, \mathrm{Co}, \mathrm{Cr}, \mathrm{Cu}, \mathrm{Mn}, \mathrm{Ni}$ and $\mathrm{Pb}$ ) were found to be in the concentration range of 0.0001 to $0.0733 \mathrm{mg} . \mathrm{Kg}^{-1}$ and thus it has been quantified by the verified ICP-AES analytical method. The relative standard deviations (RSD) are found to be in the range of 24 to 124, which is lower than the acceptance criteria (RSD is from 70 and 150\%) (USP,2007). Regarding to the toxic heavy metal including; $\mathrm{Al}, \mathrm{As}, \mathrm{Cd}, \mathrm{Co}, \mathrm{Cr}$ and $\mathrm{Pb}$, are found to be in low detection limit (LOD) or in very low concentrations under the limits allowed in olive oils. The results given in Table 7 , can be concluded to that all the olive oil samples are acceptable with high accuracy determination of very low contamination with heavy metals. This has been achieved by using a verified ICPAES analysis that is based on a simple, low cost and effective method for extraction.

metals determination in vegetable oils (De Leonardis, et al.,2000).

*Corresponding author: ${ }^{1}$ H. S. Hafez; Environmental Studies and Research Institute, University of Sadat City; Menofia, Egypt. P.O. 32897; Tel: +2 01009463473; Fax: +2 048 2600404; E:mail; hoda.hafez@esri.usc.edu.eg; https://orcid.org/0000-0002-8574-1451 


\begin{tabular}{|c|c|c|c|c|c|c|c|c|c|c|c|c|c|c|}
\hline .No. & Al & As & Ca & Cd & Co & $\mathrm{Cr}$ & $\mathrm{Cu}$ & $\mathbf{F e}$ & $\mathbf{K}$ & Mg & Mn & $\mathbf{N i}$ & $\mathbf{P b}$ & Zn \\
\hline 1 & LLOD & LLOD & 0.5552 & 0.0036 & 0.0031 & 0.0034 & 0.0228 & 0.0525 & 2.8732 & 0.0675 & LLOD & 0.0056 & 0.0068 & LLOD \\
\hline 2 & LLOD & 0.0068 & 0.7840 & LLOD & 0.0033 & LLOD & 0.0401 & 0.0349 & 0.0709 & 0.0441 & 0.0024 & 0.0057 & LLOD & 0.0243 \\
\hline 3 & 0.0083 & LLOD & 2.1273 & LLOD & 0.0035 & 0.0111 & 0.0344 & 0.2852 & 0.1032 & 0.1009 & 0.0031 & LLOD & LLOD & 0.0815 \\
\hline 4 & 0.0149 & LLOD & 2.3209 & 0.0049 & 0.0039 & 0.0128 & 0.0392 & 0.1214 & 0.8072 & 0.2965 & 0.0070 & 0.0035 & 0.0301 & 0.0619 \\
\hline 5 & LLOD & 0.0084 & 1.4781 & 0.0038 & LLOD & LLOD & LLOD & 0.1455 & 0.7710 & 0.1176 & 0.0028 & 0.0057 & LLOD & 0.0211 \\
\hline 6 & LLOD & LLOD & 1.6778 & 0.0048 & 0.0040 & 0.0660 & 0.0510 & 0.3694 & 0.1578 & 0.0882 & 0.0028 & LLOD & 0.0007 & 0.0670 \\
\hline 7 & 0.0070 & 0.0165 & 1.3779 & LLOD & 0.0028 & LLOD & 0.0390 & 0.1044 & 0.1373 & 0.1784 & 0.0006 & 0.0055 & LLOD & 0.0474 \\
\hline 8 & LLOD & 0.0066 & 1.9977 & 0.0038 & 0.0027 & 0.0046 & LLOD & 0.0939 & 0.1586 & 0.1006 & 0.0048 & LLOD & 0.0132 & 0.0286 \\
\hline 9 & LLOD & LLOD & 1.5574 & LLOD & 0.0029 & 0.0399 & 0.0489 & 0.1368 & 0.5832 & 0.1921 & LLOD & 0.0058 & 0.0179 & 0.0486 \\
\hline 10 & LLOD & 0.0158 & 2.2655 & 0.0040 & LLOD & 0.0161 & 0.0401 & 0.9440 & 0.0547 & 0.1202 & 0.0026 & LLOD & LLOD & 0.0848 \\
\hline 11 & 0.0571 & 0.0146 & 6.3779 & LLOD & 0.0019 & 0.0537 & 0.0343 & 0.3181 & 1.5045 & 0.4925 & 0.0042 & LLOD & 0.0328 & 0.1241 \\
\hline 12 & 0.0733 & LLOD & 8.3990 & 0.0068 & LLOD & 0.0186 & 0.0244 & 0.0468 & 0.3435 & 0.6313 & LLOD & 0.0282 & LLOD & 0.3243 \\
\hline 13 & 0.0515 & LLOD & 4.1455 & 0.0063 & LLOD & 0.0182 & 0.0230 & 0.1184 & 1.2572 & 0.6966 & 0.0331 & 0.0070 & 0.0104 & 0.2027 \\
\hline 14 & 0.0563 & LLOD & 4.9478 & 0.0048 & LLOD & 0.0069 & 0.0226 & 0.0419 & 0.3067 & 0.2673 & 0.0166 & 0.0263 & 0.0145 & 0.1164 \\
\hline 15 & LLOD & LLOD & 0.7330 & 0.0034 & 0.0019 & 0.0162 & 0.0103 & 0.1253 & 0.1848 & 0.0674 & LLOD & 0.0048 & 0.0265 & 0.0001 \\
\hline Min & 0.007 & 0.0066 & 0.5552 & 0.0034 & 0.0019 & 0.0034 & 0.0103 & 0.0349 & 0.0547 & 0.0441 & 0.0006 & 0.0035 & 0.0007 & 0.0001 \\
\hline Max. & 0.0733 & 0.0165 & 8.399 & 0.0068 & 0.004 & 0.066 & 0.051 & 0.944 & 2.8732 & 0.6966 & 0.0331 & 0.0282 & 0.0328 & 0.3243 \\
\hline Mean & 0.0383 & 0.0115 & 2.7163 & 0.0046 & 0.0030 & 0.0223 & 0.0331 & 0.1959 & 0.6209 & 0.2307 & 0.0073 & 0.0098 & 0.0170 & 0.0881 \\
\hline SD & 0.0274 & 0.0047 & 2.2682 & 0.0012 & 0.0007 & 0.0201 & 0.0118 & 0.2309 & 0.7670 & 0.2110 & 0.0096 & 0.0092 & 0.0109 & 0.0856 \\
\hline RSD & 71.4554 & 40.7393 & 83.5039 & 24.9685 & 24.1395 & 90.0748 & 35.5185 & 117.8692 & 123.5271 & 91.4339 & 131.6846 & 94.2319 & 64.0180 & 97.2154 \\
\hline
\end{tabular}





\section{Conclusions}

A simple, accurate, precise, Rugged, selective, Specific and stable ICP-AES method has been validated for the simultaneous determination of fourteen trace metals in fifteen olive oil samples. The selected method is linear for the determination of these metals in the range of $0.005-2.87 \mathrm{mg} \cdot \mathrm{kg}^{-1}$ and results of linearity are found to be in between 0.9962 to 0.9999 that comply with accepted criteria $\left(\mathrm{R}^{2} \geq 0.99\right)$. The method of analysis has been verified to be selective and specific for determination of targeted metals at the selected wavelengths. The limits of detection and quantification are determined for each metal and are found to be in between $(0.006 \mu \mathrm{g} / \mathrm{kg}-$ $2.32 \mu \mathrm{g} / \mathrm{kg})$ and $(0.022 \mu \mathrm{g} / \mathrm{kg}-7.6 \mu \mathrm{g} / \mathrm{kg})$ respectively. The low LOD and LOQ values of the investigated, enables the detection and quantitation of them in Olive oil samples at low concentrations. The recovery for each targeted heavy metal is between $(72.63 \%$ to $124.62 \%)$. The repeatability of the method is complied with USP acceptance criteria. Therefore, it can be concluded that the ICP-AES that is based on the proposed simple, low cost and effective method for extraction, is a powerful and valid technique for the quantitative determination of heavy metals in olive oils.

\section{Reference}

Ansari, R., Kazi, T. G., Jamali, M. K., Arain, M. B., Wagan, M. D., Jalbani, N., ... \& Shah, A. Q. (2009). Variation in accumulation of heavy metals in different verities of sunflower seed oil with the aid of multivariate technique. Food Chemistry, 115(1), 318-323.

Ball, M. J. (1979). How to choose and use a calculator. British medical journal, 1(6162), 552.

Cabrera-Vique, C., Bouzas, P. R., \& Oliveras-López, M. J. (2012). Determination of trace elements in extra virgin olive oils: A pilot study on the geographical characterisation. Food Chemistry, 134(1), 434-439.

Codex Alimentarius Commission. (2013). Codex General Standard for Contaminants and Toxins in Food and Feed. CODEX STAN 193, 1995. Food and Agriculture Organization: Rome, Italy.

Cypriano, J. C., Matos, M. A. C., \& Matos, R. C. (2008). Ultrasound-assisted treatment of palm oil samples for the determination of copper and lead by stripping chronopotentiometry. Microchemical Journal, 90(1), 26-30.

De Leonardis, A., Macciola, V., \& De Felice, M. (2000). Copper and iron determination in edible vegetable oils by graphite furnace atomic absorption spectrometry after extraction with diluted nitric acid. International journal of food science \& technology, 35(4), 371-375. 
de Souza, R. M., Leocadio, L. G., \& da Silveira, C. L. P. (2008). ICP OES simultaneous determination of $\mathrm{Ca}, \mathrm{Cu}, \mathrm{Fe}, \mathrm{Mg}, \mathrm{Mn}, \mathrm{Na}$, and $\mathrm{P}$ in biodiesel by axial and radial inductively coupled plasma-optical emission spectrometry. Analytical letters, 41(9), 1615-1622.

Díaz, T. G., Guiberteau, A., Soto, M. L., \& Ortiz, J. M. (2006). Determination of copper with 5, 5-dimethylcyclohexane-1, 2, 3-trione 1, 2-dioxime 3thiosemicarbazone in olive oils by adsorptive stripping square wave voltammetry. Food Chemistry, 96(1), 156-162.

Dugo, G., La Pera, L., La Torre, G. L., \& Giuffrida, D. (2004). Determination of Cd (II), $\mathrm{Cu}$ (II), $\mathrm{Pb}$ (II), and $\mathrm{Zn}$ (II) content in commercial vegetable oils using derivative potentiometric stripping analysis. Food Chemistry, 87(4), 639-645.

ICH, I. (2005, November). Q2 (R1): Validation of analytical procedures: text and methodology. In International Conference on Harmonization, Geneva.

Juranovic, I., Breinhoelder, P., \& Steffan, I. (2003). Determination of trace elements in pumpkin seed oils and pumpkin seeds by ICP-AES. Journal of Analytical Atomic Spectrometry, 18(1), 54-58.

Karadjova, I., Zachariadis, G., Boskou, G., \& Stratis, J. (1998). Electrothermal atomic absorption spectrometric determination of aluminium, cadmium, chromium, copper, iron, manganese, nickel and lead in olive oil. Journal of Analytical Atomic Spectrometry, 13(3), 201-204.

Martin-Polvillo, M., Albi, T., \& Guinda, A. (1994). Determination of trace elements in edible vegetable oils by atomic absorption spectrophotometry. Journal of the American Oil Chemists’ Society, 71(4), 347-353.

Nunes, L. S., Barbosa, J. T., Fernandes, A. P., Lemos, V. A., dos Santos, W. N., Korn, M. G. A., \& Teixeira, L. S. (2011). Multi-element determination of $\mathrm{Cu}, \mathrm{Fe}, \mathrm{Ni}$ and $\mathrm{Zn}$ content in vegetable oils samples by high-resolution continuum source atomic absorption spectrometry and microemulsion sample preparation. Food chemistry, 127(2), 780-783.

Raptis, S. E., Kaiser, G., \& Tölg, G. (1982). The decomposition of oils and fats in a stream of oxygen for the determination of trace elements. Analytica Chimica Acta, 138, 93-101.

Şahan, Y., Basoglu, F., \& Gücer, S. (2007). ICP-MS analysis of a series of metals (Namely: $\mathrm{Mg}, \mathrm{Cr}, \mathrm{Co}, \mathrm{Ni}, \mathrm{Fe}, \mathrm{Cu}, \mathrm{Zn}, \mathrm{Sn}, \mathrm{Cd}$ and $\mathrm{Pb}$ ) in black and green olive samples from Bursa, Turkey. Food Chemistry, 105(1), 395-399.

metals determination in vegetable oils (De Leonardis, et al.,2000).

*Corresponding author: ${ }^{1}$ H. S. Hafez; Environmental Studies and Research Institute, University of Sadat City; Menofia, Egypt. P.O. 32897; Tel: +2 01009463473; Fax: +2 048 2600404; E:mail; hoda.hafez@esri.usc.edu.eg; https://orcid.org/0000-0002-8574-1451 
Taverniers, I., Van Bockstaele, E., \& De Loose, M. (2010). Analytical method validation and quality assurance.Pharmaceutical Sciences Encyclopedia: Drug Discovery, Development, and Manufacturing, 1-48.

USP. (2007). United States Pharmacopeia. Nineteenth Revision, United States Pharmacopeial.

Voica, C., Dehelean, A., Iordache, A., \& Geana, I. (2012). Method validation for determination of metals in soils by ICP-MS. Romanian reports in Physics, 64(1), 221231.

Wenzl, T., Haedrich, J., Schaechtele, A., Piotr, R., Stroka, J., Eppe, G., \& Scholl, G. (2016). Guidance Document on the Estimation of LOD and LOQ for Measurements in the Field of Contaminants in Food and Feed. Institute for Reference Materials and Measurements (IRMM). 